\title{
Correction to: Dissipation of Turbulence in the Wake of a Wind Turbine
}

\author{
Julie K. Lundquist ${ }^{1,2} \cdot$ Ludovic Bariteau $^{3,4}$ \\ Published online: 16 May 2020 \\ (c) Springer Nature B.V. 2020
}

\section{Correction to: Boundary-Layer Meteorol (2015) 154:229-241 https://doi.org/10.1007/s10546-014-9978-3}

We recently noticed systematic typographical errors in the equations that define the best-fit lines for Figs. 4, 5, and 6.

Equation 5 should read as

$$
\log _{10}\left(\epsilon_{\text {nonwaked }}\right)=0.029 U-3.24 \text {. }
$$

Equation 6 should read as

$$
\log _{10}\left(\epsilon_{\text {waked }}\right)=0.0017 U-1.2 .
$$

Equation 7 should read as

$$
\log _{10}\left(\epsilon_{\text {nonwaked }}\right)=22.73 \sigma_{U}^{2}-3.3 .
$$

Equation 8 should read as

$$
\log _{10}\left(\epsilon_{\text {waked }}\right)=0.53 \sigma_{U}^{2}-1.25 .
$$

Equation 10 should read as

$$
\log _{10}\left(\epsilon_{\text {nonwaked }}\right)=24.38 T I-3.94 \text {. }
$$

Equation 11 should read as

$$
\log _{10}\left(\epsilon_{\text {waked }}\right)=5.58 T I-1.63 \text {. }
$$

The original article can be found online at https://doi.org/10.1007/s10546-014-9978-3.

Julie K. Lundquist

Julie.Lundquist@colorado.edu

1 Department of Atmospheric and Oceanic Sciences, University of Colorado at Boulder, Boulder, CO 80309-0311, USA

2 National Wind Technology Center, National Renewable Energy Laboratory, Golden, CO 80401-3305, USA

3 Earth System Research Laboratory, NOAA, 325 Broadway, Boulder, CO 80305-3337, USA

4 Cooperative Institute for Research in Environmental Sciences, University of Colorado Boulder, Boulder, CO 80309-0216, USA 
All notation is as defined in the original article. The errors are only typographical and therefore do not affect results or change the best-fit lines that appear in Figs. 4, 5, and 6. We apologise for any inconvenience caused. We express appreciation to Dr. Norman Wildmann for inquiring about the equations and bringing the typographical errors to our attention.

Publisher's Note Springer Nature remains neutral with regard to jurisdictional claims in published maps and institutional affiliations. 